\title{
BCA-1 is highly expressed in Helicobacter pylori-induced mucosa-associated lymphoid tissue and gastric lymphoma
}

\author{
Luca Mazzucchelli, ${ }_{1}^{1}$ Andrea Blaser, ${ }^{2}$ Andreas Kappeler, ${ }^{1}$ Patrik Schärli, ${ }^{2}$ Jean A. Laissue, ${ }^{1}$ \\ Marco Baggiolini, ${ }^{2}$ and Mariagrazia Uguccioni ${ }^{2}$
}

${ }^{1}$ Institute of Pathology, and

${ }^{2}$ Theodor Kocher Institute, University of Bern, 3012 Bern, Switzerland

Address correspondence to: Mariagrazia Uguccioni, Theodor Kocher Institute, University of Bern, Freiestrasse 1, 3012 Bern, Switzerland. Phone: 41-31-631-4158; Fax: 41-31-631-3799; E-mail: mariagrazia.uguccioni@tki.unibe.ch.

Received for publication July 13, 1999, and accepted in revised form October 6, 1999.

Infection with Helicobacter pylori $(\mathrm{Hp})$ induces the formation of lymphoid tissue in the stomach and the occasional development of primary gastric B-cell lymphomas. We have studied the expression of 2 chemokines that attract B lymphocytes, BCA-1 and SLC, in gastric tissue samples obtained from patients with chronic gastritis induced by $\mathrm{Hp}$ infection or nonsteroidal anti-inflammatory drugs, as well as from patients with $\mathrm{Hp}$-associated low-grade and high-grade gastric lymphomas. High-level expression of BCA-1 and its receptor, CXCR5, was observed in all mucosal lymphoid aggregates and in the mantle zone of all secondary lymphoid follicles in $\mathrm{Hp}$-induced gastric mucosa-associated lymphoid tissue (MALT). Follicular dendritic cells and B lymphocytes are possible sources of BCA-1, which is not expressed by $\mathrm{T}$ lymphocytes, macrophages, or $\mathrm{CD} 1 \mathrm{a}^{+}$dendritic cells. Strong expression of BCA-1 and CXCR5 was also detected in the transformed B cells of gastric MALT lymphomas. By contrast, SLC was confined almost exclusively to endothelial cells in and outside the lymphoid tissue. Only scant, occasional SLC expression was observed in the marginal zone of MALT follicles. Our findings indicate that BCA-1, which functions as a homing chemokine in normal lymphoid tissue, is induced in chronic Hp gastritis and is involved in the formation of lymphoid follicles and gastric lymphomas of the MALT type.

This article may have been published online in advance of the print edition. The date of publication is available from the JCI website, http://www.jci.org. J. Clin. Invest. 104:R49-R54 (1999).

\section{Introduction}

A characteristic feature of the chronic gastritis induced by Helicobacter pylori $(\mathrm{Hp})$ is the presence of mucosa-associated lymphoid tissue (MALT), which consists of lymphoid aggregates and organized follicles $(1,2)$. MALT is not normally found in the stomach mucosa and disappears after eradication of the infection $(3,4)$, suggesting that $\mathrm{Hp}$ is the causative agent. The mechanism that recruits lymphocytes into the $\mathrm{Hp}$ infected mucosa, leading to MALT formation and in some instances to gastric lymphomas $(5,6)$, is unknown, but a role for chemokines acting on B lymphocytes can be presumed.

The first indication that chemokines may be involved in lymphoid tissue for- mation came from the study of a putative chemokine receptor called BLR1 (7) or MDR15 (8), which is highly expressed in blood B lymphocytes and Burkitt's lymphoma cells (9). Deletion of the receptor gene in mice led to a profound disturbance of follicle and germinal center formation in the spleen and Peyer's patches (10). Receptor-deficient B lymphocytes enter Tcell areas but do not migrate further, suggesting that BLR1 is needed for their homing into B-cell areas. After identification of the ligand, a CXC chemokine called BCA-1 in humans (11) and BLC in mice (12), the receptor was renamed CXCR5. The observation that BCA-1 is selective for CXCR5 and chemotactic for human B lymphocytes (11) prompted this study.

In this paper we show that BCA-1 and its receptor, CXCR5, are both highly expressed in primary and secondary lymphoid follicles and in MALT lymphomas that develop in the $\mathrm{Hp}$-infected stomach mucosa. This finding suggests that BCA-1 is a major mediator of the long-term pathology of $\mathrm{Hp}$ infection. In addition, our observations indicate that the same chemokine can have homeostatic as well as inflammatory functions, and thus call into question a strict distinction between constitutive and inducible chemokines (13).

\section{Methods}

Tissue samples. Formaldehyde-fixed and paraffin-embedded tissue samples were obtained from 15 patients (mean age 53 years) with chronic, active $\mathrm{Hp}$-induced gastritis, 6 patients (mean age 67 years) with gastritis induced by nonsteroidal anti-inflammatory drugs (NSAIDs), and 4 individuals (mean age 35 years) with histologically normal antrum and corpus mucosa. In addition, formaldehyde-fixed and paraffinembedded tissue samples were obtained after gastrectomy from 10 patients (mean age 60 years) with primary gastric lymphoma of the MALT type. Gastritis was evaluated histologically according to a modified Sydney classification (14), and lymphomas were diagnosed by standard histological criteria and immunohistochemistry (6).

Primary antibodies. Goat anti-human BCA-1 (1:100; R\&D Systems Inc., Minneapolis, Minnesota, USA) and rabbit 


\section{Figure 1}

In situ expression of BCA-1 in chronic Hp gastritis. Expression is observed in the whole area of lymphoid aggregates (a) and is restricted to the mantle zone in secondary lymphoid follicles (c). Intermediate distribution (b) is found occasionally. (d-f) Localization of follicular dendritic cells as detected in serial sections by immunohistochemical staining for CD21. Bottom: In situ expression of BCA-1 in a secondary follicle of a normal lymph node. Antisense and sense hybridization is shown. $\times 100$ (original magnification).

anti-human CXCR5 (IgG purified, 1:100) were used to detect BCA- 1 and its receptor. The rabbit polyclonal antibody was raised against a synthetic peptide corresponding to the $\mathrm{NH}_{2}$-terminal domain (amino acids 1-55) of human CXCR5 coupled to keyhole limpet hemocyanin. Selectivity was tested on CXCR5 transfectants. No cross-reactivity was observed with cells transfected with other chemokine receptors or with human blood cell antigens. Monoclonal antibodies directed against $\mathrm{CD}^{+} \mathrm{T}$ lymphocytes (clone PS1; Novocastra Laboratories Ltd., Newcastle upon Tyne, United Kingdom), $\mathrm{CD} 20^{+} \mathrm{B}$ lymphocytes (clone L26; DAKO A/S, Glostrup, Denmark), $\mathrm{CD} 21^{+}$follicular dendritic cells (clone 1F8; DAKO A/S), CD23 $3^{+}$follicular dendritic cells (clone 1B12; Novocastra Laboratories Ltd.), $\mathrm{CD} 1 \mathrm{a}^{+}$interdigitating dendritic cells (clone 010; Immunotech, Marseilles, France), CD $31^{+}$endothelial cells (clone JC/70A; DAKO A/S), and $\mathrm{CD}^{2} 8^{+}$macrophages (clone PG-M1; DAKO A/S) were also used.

Immunohistochemistry. For BCA-1 and CXCR5 detection, formalin-fixed, paraffin-embedded sections were dewaxed, rehydrated, and then boiled in $100 \mathrm{mM}$ Tris-buffered saline $(\mathrm{pH} 9.5)$ with $5 \%$ urea in an $850-\mathrm{W}$ microwave oven for 8 minutes, followed by 2 similar treatments of 5 minutes each. Then the sections were washed in Tris-buffered saline and incubated at room temperature for 60 minutes with anti-CXCR5, or for 24 hours with anti-BCA-1. Antibodies were diluted in Tris-buffered saline containing $0.5 \%$ casein sodium salt (Sigma Chemical Co., St. Louis, Missouri, USA) and either $5 \%$ goat serum (for anti-CXCR5) or rabbit serum (for anti-BCA-1). After exposure to the primary antibody, the sections were incu-
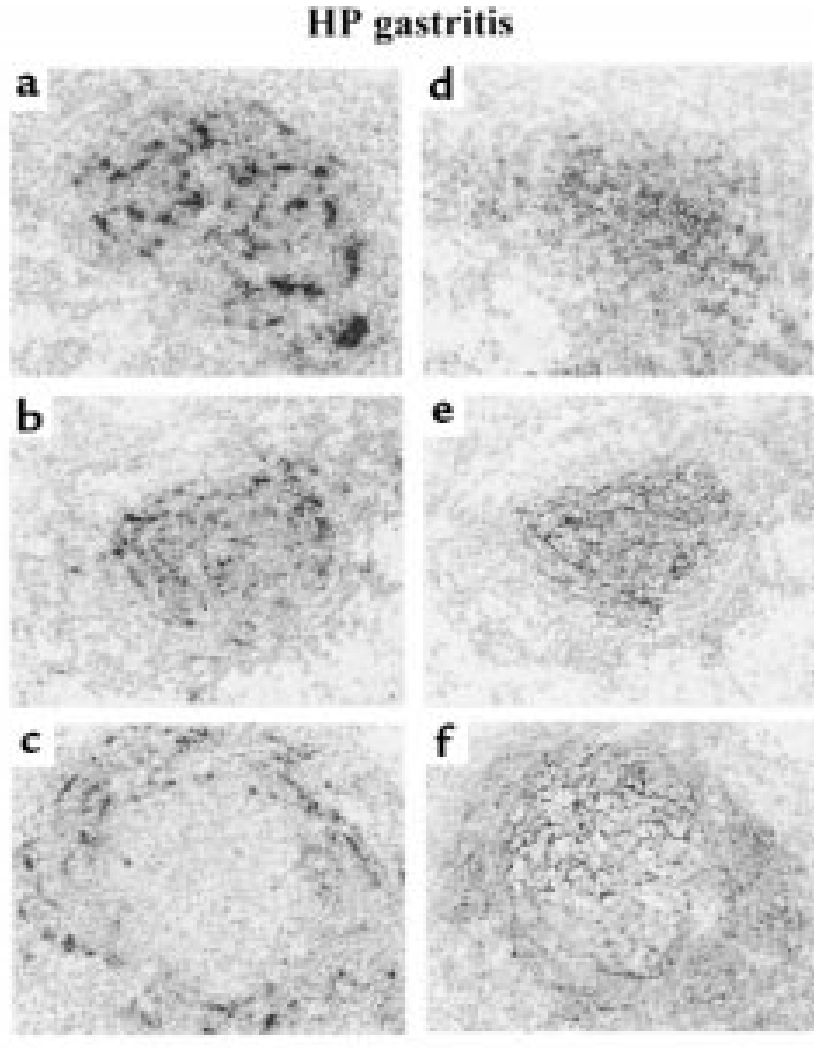

\section{Lymph node}
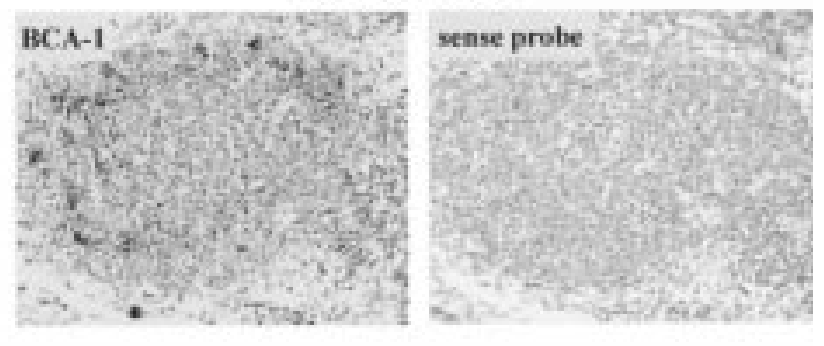

bated with a 1:200 dilution (in the same buffer as that used for the primary antibody) of biotinylated goat anti-mouse Ig (DAKO A/S) or a 1:100 dilution of biotinylated donkey anti-goat Ig (Binding Site, Birmingham, United Kingdom), and then with streptavidin-biotin complex/alkaline phosphatase (DAKO A/S) at 1:200 in Tris-buffered saline. The sections were then developed in new fuchsin-naphthol AS-BI (Sigma Chemical Co.) and counterstained with hematoxylin. Immunohistochemical staining for BCA-1 was also performed on frozen sections after fixation in cold acetone. Anti-BCA-1 was diluted at 1:50 and incubated with the sections for 60 minutes. Immunostaining for cellular markers was performed accord- ing to a standard $\mathrm{ABC}$ technique (DAKO A/S).

In situ hybridization. ${ }^{35}$ S-labeled BCA-1 and SLC RNA probes -368 bp corresponding to position -24 to 344 of the BCA-1 sequence (11), and 368 bp corresponding to position -58 to 310 of the SLC sequence (15), respectively were generated by in vitro transcription (Boehringer Mannheim $\mathrm{GmbH}$, Mannheim, Germany). Paraffin sections were dewaxed and rehydrated in graded ethanol. Protein digestion was performed with $1 \mu \mathrm{g} / \mathrm{mL}$ proteinase $\mathrm{K}$ for 30 minutes at $37^{\circ} \mathrm{C}$, and blocked with $0.1 \mathrm{M}$ glycine in PBS for $5 \mathrm{~min}$ utes. Tissue slides were postfixed in $4 \%$ paraformaldehyde and dehydrated in graded ethanol before treatment at room temperature with $0.1 \mathrm{M}$ tri- 


\section{Figure 2}

BCA-1 and CXCR5 expression in chronic Hp gastritis. (a) In situ expression of BCA-1 is shown in the mantle zone of a secondary lymphoid follicle. The sense probe control (b) and staining for B lymphocytes $\left(\mathrm{CD} 20^{+}\right)(\mathbf{c})$ are shown in serial sections of the same follicle. $\times 100$ (original magnification). BCA-1 (d) and CXCR5 (f) immunostaining is shown with the corresponding isotype-matched controls (e and $\mathbf{g}$ ). Staining of a frozen section of a tonsil ( $\mathbf{h}$ ) and control (i) shows BCA- 1 in association with small round and stellate cells, suggesting expression by lymphocytes and dendritic cells. $\times 200$ (original magnification).

ethanolamine ( $\mathrm{pH} 8.0$ ) for 3 minutes, followed by $4 \%$ acetic anhydride in $0.1 \mathrm{M}$ triethanolamine for 10 minutes. After washes in $\mathrm{H}_{2} \mathrm{O}$ and dehydration in graded ethanol, slides were air-dried and then incubated with the BCA-1 or SLC mRNA probes. In situ hybridization was performed overnight at $45^{\circ} \mathrm{C}$ with sense or antisense probes $\left(10^{6} \mathrm{cpm} / \mathrm{section}\right)$ diluted in hybridization solution (10\% dextran sulfate, $50 \%$ deionized formamide, $300 \mathrm{mM} \mathrm{NaCl}, 20 \mathrm{mM}$ Tris/HCl (pH 7.5), 5 mM EDTA, $1 \times$ Denhardt's solution, and $100 \mathrm{mM}$ DTT). After hybridization, the sections were washed with a solution of $10 \mathrm{mM}$ DTT, $50 \%$ formamide, $1 \mathrm{mM}$ EDTA ( $\mathrm{pH} 8.0$ ), and $2 \times \mathrm{SSC}$ for 30 minutes at $54^{\circ} \mathrm{C}$, followed by 2 additional washes in $2 \times$ SSC combined with $10 \mathrm{mM}$ DTT. Subsequently, slides were treated with 100,000 U/mL RNase T1 (Boehringer Mannheim $\mathrm{GmbH}$ ) and 1,000 U/mL RNase A (Boehringer Mannheim $\mathrm{GmbH}$ ) for 30 minutes at $37^{\circ} \mathrm{C}(16)$. After additional washes, tissues were dehydrated and air-dried, dipped in Kodak photo emulsion NTB-2, and exposed in the dark for 4 weeks at $4^{\circ} \mathrm{C}$. Development and fixation were performed according to the Kodak proto$\mathrm{col}$, and the sections were counterstained with Mayer's hematoxylin.

\section{Results}

Specimen histopathology. Chronic antrum inflammation with lymphoid follicles was observed in all samples of Hp gastritis. The bacteria were detected at the mucosal surface in all cases by hematoxylin and eosin or modified Giemsa staining. Infiltration by neutrophils was moderate to marked. NSAIDinduced chronic gastritis had a characteristic appearance, with occasional

\section{HP gastritis}
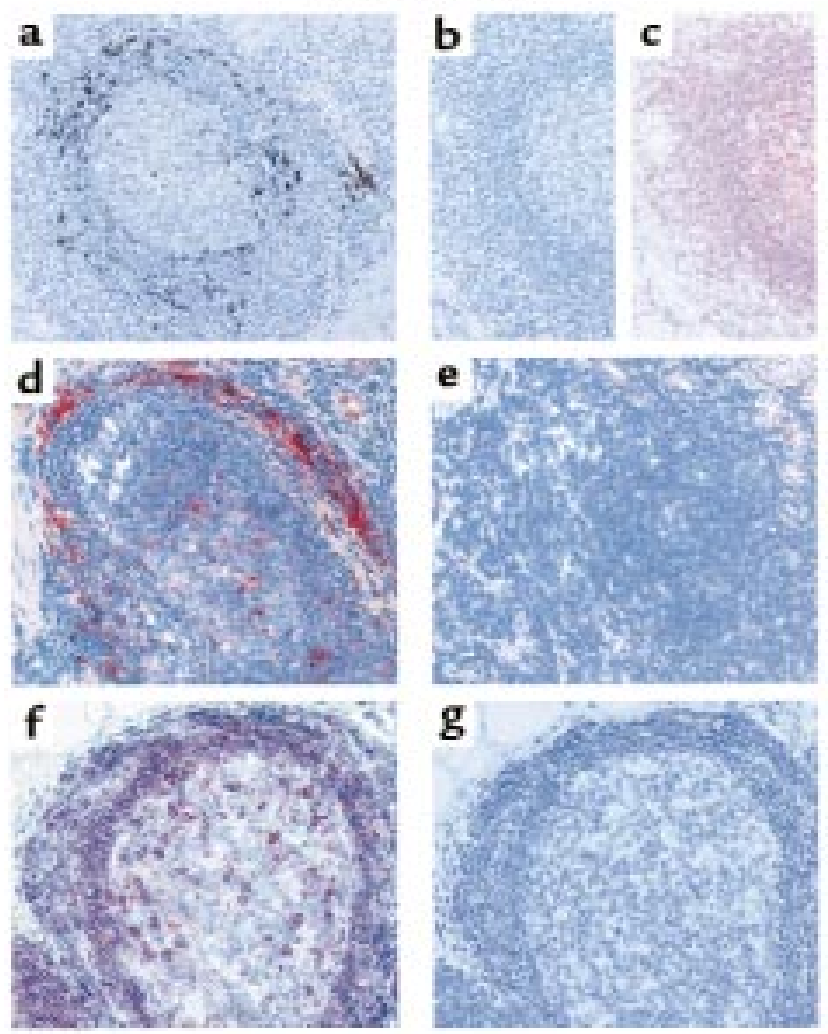

\section{Tonsil}
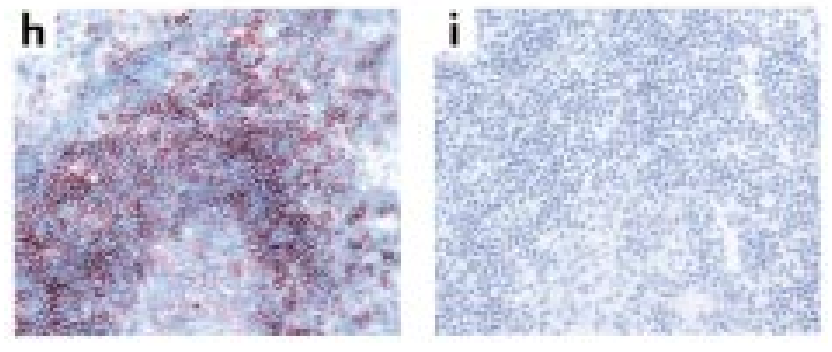

mucosal erosions. The samples of NSAID-induced gastritis and normal gastric mucosa were all $\mathrm{Hp}$-negative, both by histology and by the urease test. Samples from 10 patients with gastric lymphoma were studied. In 5 cases, high-grade lymphoma was diagnosed by the presence of sheets of transformed blasts. The other 5 cases were diagnosed as low-grade. In 4 of the 5 low-grade lymphomas, the tumor was confined to the mucosa and submucosa, whereas all high-grade lymphomas showed infiltration of the whole stomach wall. In all instances, Hp infection was confirmed histologically and chronic gastritis with lym- phoid hyperplasia was observed in the vicinity of the neoplastic tissue.

$H p$ and NSAID gastritis. Marked BCA-1 expression was found in all samples of $\mathrm{Hp}$ gastritis. Expression was mainly confined to lymphocyte aggregates and to primary and secondary follicles. BCA-1 transcripts were evenly distributed in nonorganized B lymphocyte aggregates but were restricted to the mantle zone in secondary lymphoid follicles. An intermediate arrangement was also observed, which presumably reflects the process of organization of the aggregates into lymphoid follicles (Figure 1). The degree of BCA-1 expres- 


\section{Figure 3}

Expression of BCA-1 and CXCR5 in gastric MALT lymphomas. In situ expression of BCA-1 in (a) low-grade lymphoma with surrounding normal gastric mucosa, $\times 40$ (original magnification); and in high-grade lymphoma (b and c), $\times 200$ and $\times 400$, respectively (original magnification). Immunostaining of BCA-1 and CXCR5 in highgrade lymphoma ( $\mathbf{d}$ and $\mathbf{e}), \times 400$ and $\times 200$, respectively (original magnification).

sion as assessed by the hybridization signals was not related to the number of bacteria detected at the mucosal surface, or to the presence of infiltrating neutrophils and eosinophils in the lamina propria. The distribution of BCA-1-producing cells in $\mathrm{Hp}$-induced gastric MALT is similar to that observed in normal lymphoid tissues, as shown in Figure 1. BCA-1 transcripts were not detected in endothelial cells or in the epithelial cells of the mucosa, even in the vicinity of colonizing bacteria. Occasional BCA-1-expressing cells (accounting for less than $0.5 \%$ of the total as determined by image analysis) were found outside the MALT in the lamina propria of the antrum and the corpus in Hp- and NSAID-induced gastritis, but were also in control specimens. The significance of this rare expression, which is not related to $\mathrm{Hp}$ infection, is unknown.

To identify the cells that produce BCA-1, we analyzed serial sections of several secondary gastric MALT follicles by immunohistochemistry. As shown in Figures 1 and 2, BCA-1 transcripts were found in areas containing many follicular dendritic cells as evidenced by immunoreactivity for CD21, and in areas where B lymphocytes accumulate. The data obtained on examination of nearly 50 MALT follicles in serial sections were consistent with those presented in Figure 2. $\mathrm{T}$ lymphocytes $\left(\mathrm{CD}^{+}\right)$, macrophages $\left(\mathrm{CD}^{+} 8^{+}\right)$, endothelial cells $\left(\mathrm{CD} 31^{+}\right)$, and $\mathrm{CD} 1 \mathrm{a}^{+}$dendritic cells were also present in the MALT, but their distribution differed markedly from that of cells expressing BCA-1 (data not shown). Immunohistochemical studies were carried out to assess the expression of the BCA-1 and CXCR5 proteins. As shown in Figure 2, BCA-1 was confined mainly to the mantle zone of lymphoid follicles. The reticu-
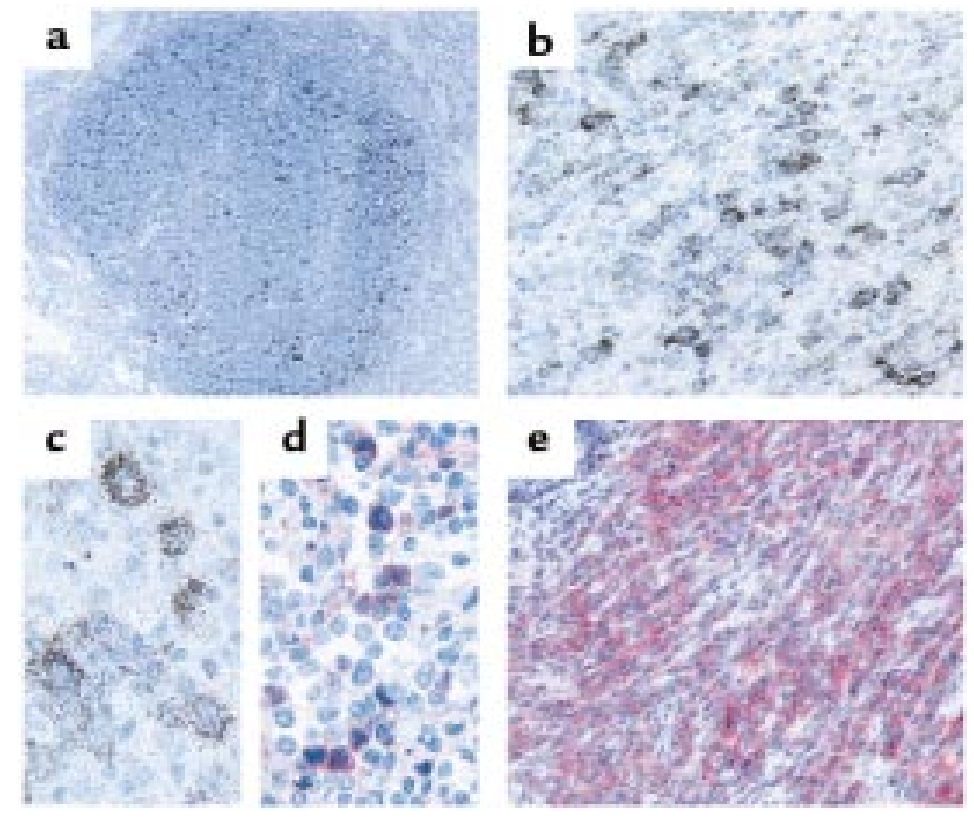

lar appearance of the staining is consistent with BCA-1 production by follicular dendritic cells. CXCR5 was expressed by lymphocytes of the mantle zone and by occasional centroblastlike cells within the germinal centers (Figure 2). BCA-1 staining was also analyzed in human tonsils using frozen sections to avoid possible artifacts from formalin fixation. In these preparations, intense staining was observed not only in the dendritic cells, but also in the lymphocytes of the mantle zone. Lymphocyte BCA-1 reactivity may indicate that the chemokine is produced by $\mathrm{B}$ lymphocytes, or may simply reflect its binding to CXCR5.

Gastric MALT lymphomas. In view of the seemingly prominent role of BCA-1 in chronic Hp gastritis, we also analyzed the expression of this chemokine in the MALT lymphomas that may develop as the disease progresses. Prominent BCA- 1 expression assessed at the mRNA and protein level was found in the neoplastic tissue, which was devoid of follicular dendritic cells, as indicated by the lack of immunostaining with antibodies directed against CD21 and CD23 (data not shown). In both stages, BCA-1 appears to be expressed and produced predominantly by the neoplastic cells. In Figure 3 , BCA-1 expression is clearly visible in a low-grade lymphoma that contrasts with the adjacent mucosa, where no expression was found. Evenly distributed BCA-1 expression is found in high-grade lymphomas, where the transformed blasts were the major source of the chemokine (Figure 3). Intensity of expression varied somewhat among the blasts; numerous small mononuclear cells within the tumor tissue were negative. The expression of CXCR5 was even more pronounced and was evenly distributed, suggesting that the BCA-1 receptor is present in transformed B cells as well as in the infiltrating lymphocytes.

SLC expression in gastric MALT and lymphomas. The chemokine SLC is also known to attract B lymphocytes and to be involved in the development of nodal and extranodal lymphoid tissues (17-19). Previous studies of normal lymph nodes showed that SLC is present at the outer rim of follicles and in the interfollicular area (18). This distribution is in striking contrast with that found in the MALT of the Hp-infected gastric mucosa, where only occasional, scant expression of SLC is observed (Figure 4). SLC gene expression was regularly found in endothelial cells throughout the mucosa and the submucosa. However, no expression was detected in epithelial cells. In low- and high-grade lymphomas, as in the non-neoplastic gastric MALT, the expression of SLC and 


\section{Figure 4}

In situ expression of SLC in chronic $\mathrm{Hp}$ gastritis (a) and in high-grade lymphoma (b). SLC expression is rare in $\mathrm{Hp}$ gastritis (arrows) and is confined to endothelial cells in the lymphoma. $\times 100$ (original magnification).
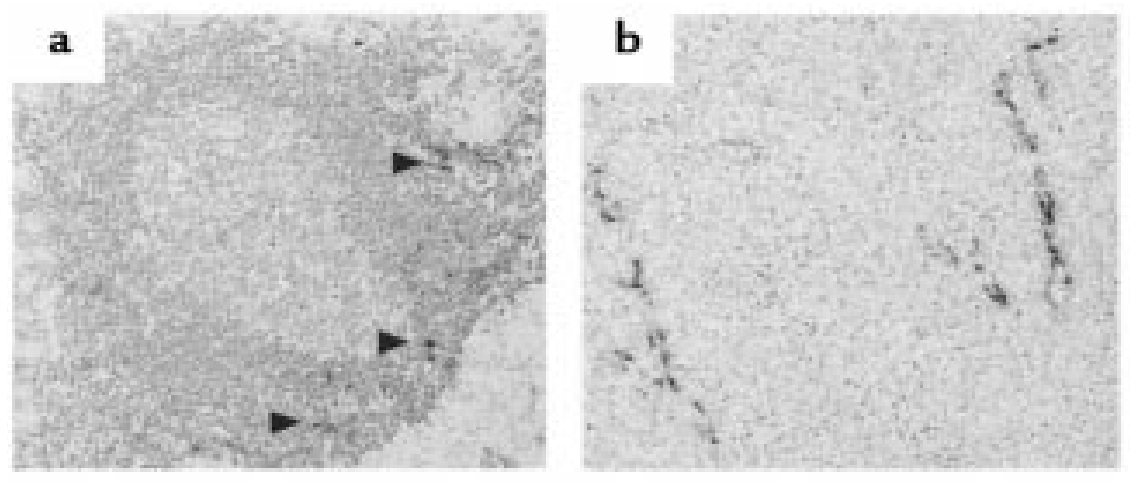

express high levels of BCA-1 may explain why MALT lymphomas have a relatively low propensity to infiltrate neighboring tissues. Because the neoplastic cells strongly express CXCR5, it is conceivable that BCA-1 may contribute to their retention within the gastric mucosa. Contributing to the same line of thought is the demonstration of lymphocyte homing receptors and vascular addressins in lowgrade MALT lymphoma (24). Furthermore, it is possible that BCA-1 expression in gastric MALT lymphomas is linked to their dependence on chronic antigen exposure (25).

Of particular interest is the demonstration that BCA-1 is not expressed by the mucosal epithelial cells, which are known to produce other CXC chemokines such as IL-8, ENA78, and GRO $\alpha$ upon exposure to $\mathrm{Hp}$ (26-28). Inflammatory chemokines released by epithelial cells may attract immature dendritic cells to mucosal sites, where bacterial products induce their maturation and activation (29). Our findings are compatible with the possibility that mature dendritic cells release BCA-1 and serve as nucleation sites for the onset of a humoral immune response and the development of gastric MALT.

The demonstration that BCA- 1 is highly expressed in the context of the infection-dependent formation of gastric MALT and MALT lymphomas brings up a new aspect of chemokine biology. Up to now, inflammatory and homing (homeostatic) chemokines have been considered to be 2 functionally separate classes (30). BCA-1 has properties of both classes: it is constitutively expressed in lymphoid tissues where it regulates the homing of
B lymphocytes $(11,12)$, but it is also induced, like an inflammatory chemokine, in the $\mathrm{Hp}$-infected mucosa and appears to be involved in the pathology of chronic Hp infection.

\section{Acknowledgments}

The authors thank B. Moser for the BCA-1 probe, and J. Gebbers, Institute of Pathology, Kantonspital, Lucerne, Switzerland for providing archival tissue. This work was supported by Swiss National Science Foundation grants 31-52427.97 (to L. Mazzucchelli) and 31-055996.98 (to M. Baggiolini).

1. Stolte, M., and Eidt, S. 1989. Lymphoid follicles in antral mucosa: immune response to Campylobacter pylori? J. Clin. Pathol. 42:1269-1271.

2. Genta, R.M., and Hamner, H.W. 1994. The significance of lymphoid follicles in the interpretation of gastric biopsy specimens. Arch. Pathol. Lab. Med. 118:740-743.

3. Genta, R.M., Hamner, H.W., and Graham, D.Y. 1993. Gastric lymphoid follicles in Helicobacter pylori infection: frequency, distribution, and response to triple therapy. Hum. Pathol. 24:577-583.

4. Genta, R.M., Lew, G.M., and Graham, D.Y. 1993. Changes in the gastric mucosa following eradication of Helicobacter pylori. Mod. Pathol. 6:281-289.

5. Wotherspoon, A.C. 1998. Helicobacter pylori infection and gastric lymphoma. Br. Med. Bull. 54:79-85.

6. Isaacson, P.G. 1996. Recent developments in our understanding of gastric lymphomas. Am. J. Surg. Pathol. 20:(Suppl. 1):S1-S7.

7. Dobner, T., Wolf, I., Emrich, T., and Lipp, M. 1992. Differentiation-specific expression of a novel G protein-coupled receptor from Burkitt's lymphoma. Eur. J. Immunol. 22:2795-2799.

8. Barella, L., Loetscher, M., Tobler, A., Baggiolini, M., and Moser, B. 1995. Sequence variation of a novel heptahelical leucocyte receptor through alternative transcript formation. Biochem. J. 309:773-779.

9. Förster, R., Emrich, T., Kremmer, E., and Lipp, M. 1994. Expression of the G-protein-coupled receptor BLR1 defines mature, recirculating B cells and a subset of T-helper memory cells. Blood. 84:830-840.

10. Förster, R., et al. 1996. A putative chemokine receptor, BLR1, directs $B$ cell migration to defined lymphoid organs and specific anatomic compartments of the spleen. Cell. 87:1037-1047.

11. Legler, D.F., et al. 1998. B cell-attracting 
chemokine 1, a human CXC chemokine expressed in lymphoid tissues, selectively attracts B lymphocytes via BLR1/CXCR5. J. Exp. Med. 187:655-660.

12. Gunn, M.D., et al. 1998. A B-cell-homing chemokine made in lymphoid follicles activates Burkitt's lymphoma receptor-1. Nature. 391:799-803.

13. Sallusto, F., Lanzavecchia, A., and Mackay, C.R. 1998. Chemokines and chemokine receptors in T-cell priming and Th1/Th2-mediated responses. Immunol. Today. 19:568-574.

14. Dixon, M.F., Genta, R.M., Yardley, J.H., and Correa, P. 1996. Classification and grading of gastritis. The updated Sydney System. International Workshop on the Histopathology of Gastritis, Houston 1994. Am. J. Surg. Pathol. 20:1161-1181.

15. Nagira, M., et al. 1997. Molecular cloning of a novel human CC chemokine secondary lymphoid-tissue chemokine that is a potent chemoattractant for lymphocytes and mapped to chromosome 9p13. J. Biol. Chem. 272:19518-19524.

16. Hofstetter, W., et al. 1992. Detection of transcripts for the receptor for macrophage colonystimulating factor, c-fms, in murine osteoclasts. Proc. Natl. Acad. Sci. USA. 89:9637-9641.

17. Gunn, M.D., et al. 1998. A chemokine expressed in lymphoid high endothelial venules promotes the adhesion and chemotaxis of naive T lympho- cytes. Proc. Natl. Acad. Sci. USA. 95:258-263.

18. Willimann, K., et al. 1998. The chemokine SLC is expressed in $\mathrm{T}$ cell areas of lymph nodes and mucosal lymphoid tissues and attracts activated $\mathrm{T}$ cells via CCR7. Eur. J. Immunol. 28:2025-2034.

19. Nagira, M., et al. 1998. A lymphocyte-specific CC chemokine, secondary lymphoid tissue chemokine (SLC), is a highly efficient chemoattractant for B cells and activated T cells. Eur. J Immunol. 28:1516-1523.

20. Zucca, E., et al. 1998. Molecular analysis of the progression from Helicobacter pylori-associated chronic gastritis to mucosa-associated lymphoid-tissue lymphoma of the stomach. N. Engl. J. Med. 338:804-810.

21. Nakamura, S., et al. 1998. B-cell monoclonality precedes the development of gastric MALT lymphoma in Helicobacter pylori-associated chronic gastritis. Am. J. Pathol. 152:1271-1279.

22. Baggiolini, M., Dewald, B., and Moser, B. 1994. Interleukin-8 and related chemotactic cytokines-CXC and CC chemokines. Adv. Immunol. 55:97-179.

23. Ngo, V.N., et al. 1999. Lymphotoxin alpha/beta and tumor necrosis factor are required for stromal cell expression of homing chemokines in B and $\mathrm{T}$ cell areas of the spleen. J. Exp. Med. 189:403-412.
24. Dogan, A., Du, M., Koulis, A., Briskin, M.J., and Isaacson, P.G. 1997. Expression of lymphocyte homing receptors and vascular addressins in lowgrade gastric B-cell lymphomas of mucosa-associated lymphoid tissue. Am. J. Pathol. 151:1361-1369.

25. Hussell, T., Isaacson, P.G., Crabtree, J.E., and Spencer, J. 1993. The response of cells from lowgrade B-cell gastric lymphomas of mucosa-associated lymphoid tissue to Helicobacter pylori. Lancet. 342:571-574.

26. Crabtree, J.E., Peichl, P., Wyatt, J.I., Stachl, U., and Lindley, I.J.D. 1993. Gastric interleukin-8 and IgA IL-8 autoantibodies in Helicobacter pylori infection. Scand. J. Immunol. 37:65-70.

27. Shimoyama, T., Everett, S.M., Dixon, M.F., Axon, A.T., and Crabtree, J.E. 1998. Chemokine mRNA expression in gastric mucosa is associated with Helicobacter pylori cagA positivity and severity of gastritis. J. Clin. Pathol. 51:765-770.

28. Suzuki, H., et al. 1998. Enhanced levels of C-X-C chemokine, human GROalpha, in Helicobacter pylori-associated gastric disease. J. Gastroenterol. Hepatol. 13:516-520.

29. Sallusto, F., and Lanzavecchia, A. 1999. Mobilizing dendritic cells for tolerance, priming, and chronic inflammation. J. Exp. Med. 189:611-614.

30. Baggiolini, M. 1998. Chemokines and leukocyte traffic. Nature. 392:565-568. 